\title{
Kajian Stilistika-Pesantren Pada Wasiat Renungan Masa Pengalaman Baru Tgkh. Zainuddin Abdul Majid
}

\author{
Ernaliana $^{1}$, Rusdiawan ${ }^{2}$, Saharudin $^{3}$ \\ ${ }^{123}$ Universitas Mataram, Mataram \\ Emali: ernaliana73@gmail.com, ${ }^{2}$ rusdiawan@live.com, ${ }^{3}$ din_linguistik@unram.ac.id
}

\begin{abstract}
The research aims to analyze the islamic boarding school language and the meaning of Zainuddin Abdul Majid poems with a literature study and analyzed using content analysis methodology by using the semiotic perspective of Charles Sanders Peirce theory. The results of the study found several things including: 1) the poems used a lot of islamic typical words/phrases, namely key words in Islamic treasures that were identical to Arabic; 2) the form of words/phrases Islamic typical words which the author used tended to be simple, namely from 50 words/phrases. typical phrases of Islamic typical are 25 elements of icons, 20 elements of indexes, and 5 elements of symbols, 3) The typical words/phrases of islamic in poetry have different meanings according to the text and context.
\end{abstract}

Keyword: stylistic, Islamic borading school, Islamic view

Abstrak. Penelitian ini bertujuan untuk menganalisis gaya bahasa khas pesatren dan kandungan makna dalam syair Wasiat Renungan Masa Pengalaman Baru (WRMPB) karya TGKH. Zainuddin Abdul Majid. Penelitian ini merupakan penelitian studi Pustaka dan dianalisis menggunakan content analysis yaitu dengan menggunakan cara pandang semiotika Teori Charles Sanders Peirce. Hasil penelitian menemukan beberapa hal diantaranya: 1) syair WRMPB banyak menggunakan kata/frasa khas pesantren yaitu kata-kata kunci dalam khazanah keislaman yang identik dengan bahasa Arab 2) bentuk kata/frasa khas pesantren yang pengarang gunakan cendrung sederhana, yaitu dari $50 \mathrm{kata} /$ frasa khas pesantren terdapat 25 unsur ikon, 20 unsur indeks, dan 5 unsur simbol, 3) Kata/frasa khas pesantren pada syair memiliki makna yang berbeda-beda sesuai dengan teks dan konteksnya.

Kata kunci: stilistika-pesantren, wasiat renungan masa, pandangan Islam

\section{PENDAHULUAN}

Bahasa dalam karya sastra digunakan sebagai wahana komunikasi yang bersifat kreatif dan imajinatif. Nilainya tidak diukur dari makna saja melainkan estetika pengarang dan diksi yang digunakannya. Gaya bahasa sangat erat kaitannya dengan karya sastra sejenis puisi yang kaya dengan nilai keindahan (Ratna, 2016, p. 13; Alisyahbana, 1950, p. 46). Sebagai salah satu karya sastra, puisi merupakan salah satu objek utama kajian stilistika, karena menggunakan bahasa secara khas dengan medium terbatas. Penggunaan kata yang padat dan pekat, dapat mewakili pesan seperti sebuah cerpen atau novel yang terdiri atas ratusan bahkan ribuan halaman. Gaya bahasa memiliki perkembangan yang dahsyat termasuk perkembangan gaya bahasa forensik. Gaya bahasa ini bertujuan untuk mengoperasi kandungan dari sebuah karya sastra (Hernandez, 2017, p. 455).
Karya sastra yang sangat populer dikalangan masyarakat lokal adalah syair. Syair merupakan jenis puisi lama yang dibawa oleh orang-orang Persia ke Indonesia. Syair berasal dari Bahasa Arab yaitu "syu'ur" atau "syi'ir yang berarti nyanyian atau qasidah (Akmal, 2015, p. 160). Bahasa dalam syair terkesan lampau dan relatif mengandung cerita yang diungkap dengan kalimat dan bunyi-bunyi yang indah (Alisyahbana, 1950, p. 46). Oleh karena itu, para ulama seperti Walisongo menggunakan syair sebagai media dalam meyebarkan Islam. Misalnya, Sunan Kalijaga, Sunan Bonang, Sunan Drajat, dan Sunan Kudus menyebarkan Islam dengan menggunakan media wayang serta musik gamelan, sedangkan Sunan Muria melalui syair/tembang yang dikarangnya. Proses dakwah tersebut, kemudian berkembang menjadi majelis ilmu sebagaimana pesantren (Rubini, 2015).

Salah satu tokoh pesantren yang popular dengan karya sastranya adalah TGKH. 
Zainuddin Abdul Majid (TGKH. Zam). Syairsyairnya ditulis dalam kombinasi tiga Bahasa yaitu Bahasa Indonesia, Arab, dan Sasak. Ditambah lagi dengan makna syair yang diteks dan dikontekstualisasikan atas pengalaman hidup, kondisi sosial, budaya, dan spiritual yang dialami langsung olehnya. Kolaborasi ketiga bahasa tersebut menggambarkan tingginya tingkat kreativitas pengarang dalam membuat karya sastra. Salah satu karya sastranya adalah syair WRMPB.

WRMPB merupakan syair berisi wasiat yang diperuntukkan untuk tiga kelompok. Wasiat pertama ditujukan kepada jamaahnya, kedua ditujukan kepada anak keturunan dan abituren, dan yang ketiga merupakan wasiat tambahan. Agar mudah dihapal, TGKH. Zam memusikalisasinya menjadi lagu wajib yang selalu disampaikan di setiap majelis organisasi. Meskipun demikian, banyak santri/jamaah belum memahami makna dan pesan yang disampaikan dalam wasiat tersebut, mereka hanya menikmatinya sebagai karya sastra. Dari ke-3 bagian wasiat tersebut, gaya bahasa yang digunakan banyak mengandung gaya bahasa khas pesantren.

Gaya bahasa khas pesantren merupakan kata-kata/istilah kunci yang digunakan dalam Islam. Contoh gaya bahasa pesantren dapat dilihat dari syair tambahan berikut:

Aduh sayang!

Tuntut olehmu halal dan bathal

Pada Ulama' yang memang terkenal

Janganlah angkuh bermain akal

"ADAT TELUK TIMBUNAN KAPAL"

Syair di atas memiliki kosakata yang akrab dengan dunia pesantren seperti kata "halal", "bathal", dan "Ulama". Kata halal berarti diizinkan, misalnya dalam hal makanan, umat Islam mengonsumsi makanan halal, bukan makanan yang diizinkan. Begitu pula dengan kata "bathal" dan ulama yang merupakan bahasa/istilah yang sering digunakan dalam Islam. Itu sebabnya, gaya bahasa pada contoh syair di atas dapat dikatakan menggunakan gaya bahasa pesantren karena diksi yang digunakan adalah kata/istilah yang akrab dengan Islam. Selain menggunakan gaya bahasa pesantren, baris ke-4 pada syair di atas juga merupakan kesimpulan yaitu jangan hanya memainkan akal karena sesuatu hal tidak akan selesai hanya dengan memainkan akal. Selain itu belajarlah dan meminta nasihat dalam hidup kepada alim ulama.

Ketertarikan menggunakan syair WRMPB sebagai objek penelitian tidak hanya dirasakan oleh peneliti, melainkan dirasakan juga oleh peneliti terdahulu yang mengunakan syair WRMPB sebagai objek. Seperti yang tercermin dalam penelitian berbagai literatur berikut: Abdul Nasip, dkk (2019) dalam tesisnya menggunakan objek WRMPB Tinjauan Hermeneutika yang memfokuskan pada Nilai Pendidikan, Sosial, Kultural, dan Spiritual. Herman Wijaya (2013, p. 65) mengkaji lagu syair WRMPB dari aspek kontekstual dan situasi serta aspek gramatikal dan leksikal. Munadi (2015) mengkaji tentang nilai-nilai pendidikan karakter pada syair WRMPB. Izzatillah (2019) mengkaji lagu syair WRMPB pada ranah estetika Islam; dan Hidayati (2017) mendalami tentang konsep Pendidikan ahlak pada syair WRMPB.

Setelah melakukan penelaahan terhadap penelitian terdahulu di atas, peneliti memperoleh gap dengan penelitian yang akan menjadi fokus peneliti, diantaranya adalah: (a) belum tergambar gaya bahasa pesantren sebagai ciri kekhasan teks WRMPB, (b). belum dijelaskan makna gaya bahasa pesantren yang terdapat dalam syair WRMPB.

Berdasarkan uraian latar belakang di atas, peneliti bermaksud untuk mengkaji secara mendalam tentang kajian stilistika. Dalam kajian stilistika, peneliti akan memfokuskan pada gaya bahasa pesantren yang terdapat dalam syair WRMPB karya TGKH. Zam. Penelitian ini menggunakan penelitian kualitatif, yaitu dengan menggunakan studi kepustakaan. Studi kepustakaan digunakan karena didukung oleh sumber data yang sudah terdokumentasi dalam buku. Selain itu, studi lapangan juga digunakan peneliti untuk mengkonfirmasi pada informaninforman yang kredibel dan akuntabel.

\section{LANDASAN TEORI}

Kerangka teoritis yang digunakan dalam penelitian ini adalah teori stilistika dan sastra pesantren. Teori ini akan menjembatani peneliti dalam menganalisis gaya bahasa khas pesantren dan makna syair yang mengandung gaya bahasa khas pesantren dalam syair WRMPB. 


\section{Stilistika}

Stilistika berasal dari Bahasa Inggris yaitu stylistic. Stilistika merupakan studi mengenai gaya bahasa yang digunakan dalam sebuah karya sastra berupa pengungkapan ide pengarang yang diekspresikan melalui pilihan kata yang menjadi ciri khas pengarang itu sendiri. Gaya bahasa tersebut merupakan efek seni yang dipengaruhi perasaan pengarang. Dengan kata lain stilistika merupakan studi tentang bahasa dan sastra dan menajdi salah satu dari pendekatan literature, dalam hal ini, stilistika mengambil karya sastra sebagai teks, memahami pesan yang ingin disampaikan oleh penulis (Tariq, 2018: 46-48).

Stilistika secara umum dapat diartikan sebagai studi tentang gaya bahasa dan pola kebahasaan yang digunakan dalam suatu teks (sastra) (Al Fajri, 2017) Stilistika menurut Ratna (2009: 167) diartikan sebagai ilmu yang berkaitan dengan gaya dan gaya bahasa, tetapi pada umumnya lebih mengacu pada gaya bahasa. Dalam kajian bahasa dan sastra, stilistika berarti cara penggunaan bahasa khas yang menimbulkan efek tertentu yang berkaitan dengan aspek-aspek keindahan.

Sebagai ilmu tentang gaya, stilistika juga merupakan salah satu cabang ilmu bidang kritik sastra. Gaya mewakili semua teks bukan hanya bahasa tertentu atau karya sastra saja, melainkan gaya adalah ciri-ciri, standar bahasa, dan ekspresi. Gaya bahasa selalu diidentikkan dengan karya sastra terutama puisi, karena puisilah yang dianggap memiliki penggunaan bahasa paling khas. Pemilihan kata dalam sebuah puisi dapat menentukan kedalaman makna dan pesan yang ingin disampaikan pengarang. Oleh karena itu, gaya bahasa mencakup berbagai figur bahasa seperti: metafora, simile, antithesis, hiperbola, dan paradoks (Minderop, 2005: 51). Keterkaitan tersebut bahkan menyebutkan bahwa sumber data utama sebuah gaya bahasa adalah karya sastra.

Pada tataran analisis, stilistika merupakan ilmu untuk memecahkan objek yaitu gaya, gaya bahasa, dan majas. Pada saat peneliti menganalisis berbagai masalah yang berkaitan dengan objek, maka ilmu yang digunakan adalah stilistika (Ratna, 2016: 169). Dengan kata lain, stilistikalah yang dapat mengungkap hakikat dan cara-cara penggunaan bahasa pengarang secara keseluruhan. Dalam hal ini analisis gaya cenderung mengeksplorasi dan menjelaskan pilihan-pilihan tertentu yang dibuat oleh penulis / penulis dalam pemilihan kata dan struktur kalimat (Khan, dkk. 2015).

\section{Gaya bahasa}

Pada dasarnya karya sastra baik gaya maupun gaya bahasa memegang peranan penting. Seperti yang dipaparkan sebelumnya bahwa gaya berkaitan dengan masalah umum penulisan, penyajian, komposisi, struktur pencitraan termasuk cara penampilan karakter huruf, cover, bentuk dan ukuran penulisan atau buku guna untuk menarik minat pembaca. Hal ini senada dengan yang diungkapkan oleh Leech dan Short (2007) yang juga menjelaskan gaya sebagai cara penyampaian pesan kepada pembaca. Gaya adalah keseluruhan cara yang dilakukan dalam aktivitas kehidupan sehari-hari baik kegiatan jasmaniah maupun rohaniah, lisan maupun tulisan (Ratna, 2016: 63).

Gaya bahasa menurut Kamus Besar Bahasa Indonesia adalah pemanfaatan atas kekayaan bahasa oleh seseorang baik dalam bentuk lisan maupun tulisan, pemakaian ragam tertentu untuk memperoleh efek tertentu, keseluruhan ciri-ciri bahasa sekelompok penulis sastra, cara khas dalam menyatakan pikiran dan perasaan yang diungkapkan baik dalam bentuk lisan maupun tulisan (Depdikbud, 1995: 297). Gaya bahasa juga diartikan sebagai bahasa yang bermula dari bahasa yang biasa digunakan dalam gaya tradisional dan literal untuk menjelaskan orang atau objek (Albertine, 2005: 51). Dengan gaya bahasa, penulis atau penutur bermaksud menjadikan paparan bahasanya menarik, kaya, padat, jelas, dan lebih mampu menekan gagasan yang ingin disampaikan, menciptakan suasana tertentu, dan menampilkan efek estetis.

Gaya bahasa sangat berkaitan erat dengan aspek keindahan. Proses penciptaan gaya bahasa jelas disadari oleh penulisnya. Untuk memperoleh aspek keindahan secara maksimal penulis memilih dan memilah kata-kata secara berulang-ulang. Inspirasi tidak selalu terjadi secara tiba-tiba, secara serta merta. Meskipun intensitasnya tinggi tetapi gaya tetap dibedakan oleh kualitasnya. Analisis gaya mengacu pada penerapan konsep dari linguistik dan disiplin 
ilmu terkait dalam interpretasi sampel komunikasi melalui bahasa (Buena, 2019: 68). Tujuan dari gaya penulisan komparatif adalah untuk mempelajari ciri-ciri gaya suatu gaya bahasa dibandingkan dengan bahasa lain (Brini, 2021)

\section{Stilistika Pesantren}

Pada dasarnya stilistika pesantren dan stilistika pada umumnya tidak memiliki perbedaan yang prinsipil. Aspek-aspek yang dikaji dalam stilistika pesantren sama dengan aspek-aspek yang dikaji dalam stilistika pada umumnya. Stilistika pesantren memiiki ranah kajian yang berfokus pada kata/frase khas pesantren. Bahasa khas pesantren cendrung menggunakan Bahasa bernuansa islam dan berasal dari Bahasa Arab, seperti Ikhwan/akhwat untuk laki-laki dan perempuan, jazakallahu khairan untu mengucapkan termakasih, dan lain sebagainya.

Pesantren selalu diidentikkan dengan lembaga pendidikan Islam. Istilah pesantren sangat dekat dengan kiyai, ustazah, pondok dan asrama. Pesantren juga populer dengan kajian kitab kuningnya dan banyak lagi. Sebagai cerminan pendidikan tradisional di Indonesia yang sejarahnya telah mengakar secara berabadabad jauh sebelum Indonesia merdeka dan sebelum kerajaan Islam berdiri, pesantren sudah mulai diperkenalkan oleh para wali yang menyebarkan Islam. Untuk memahami pengertian pondok pesantren, beberapa pendapat para ahli diantaranya berpandangan sebagai berikut:

Secara terminologis, Pesantren merupakan tempat dimana Islam diajarkan (Siradj, 1999: 85). Adapun pesantren menurut Noor (2006: 14) Pesantren merupakan Lembaga Pendidikan Islam yang minimal terdiri atas kiyai, Masjid-Pondok atau Asrama. Kiyai sebagai ustaz dan Pembina, Masjid sebagai tempat ibadah dan asrama sebagai tempat tinggal para santri. Ada prasyarat yang harus dipenuhi sebagai bagian dari pondok pesantren umumnya adalah seorang kiyai atau ustaz adalah orang yang dianggap mampu menguasai ilmu-ilmu agama dan mengajarkan santri dengan berbagai fasilitas yang dimiliki lainnya (Raharjo,1994: 18).

Berdasarkan pendapat ahli di atas, pondok pesantren diartikan sebagai Lembaga
Pendidikan Islam tradisional yang didalamnya terdapat kiyai, ustaz, asrama dan santri yang melaksanakan kegiatan belajar mengajar terutama ilmu-ilmu agama.

Sebagai sebuah lembaga pendidikan Islam, pondok pesantren dianggap sebagai lembaga pendidikan Islam tradisional. Tradisi pesanten adalah sistem Pendidikan Islam yang tumbuh sejak awal kedatangan Islam ke Indonesia. Tujuan pendikan pesantren bukan untuk mengejar kepentingan kekuasaan, uang dan keagungan duniawi, tetapi menanamkan mereka bahwa belajar adalah semata-mata kewajiban dan pengabdian kepada Tuhan. Diantara cita-cita Pendidikan pesantren adalah latihan untuk dapat berdiri sendiri dan membina diri agar tidak menggantungkan sesuatu terhadap orang lain kecuali kepada sang pencipta. (Dhofier, 2011: 44).

Adapun elemen pesantren terdiri atas Elemen-elemen pesantren terdiri atas lima unsur yaitu: pondok, Masjid, santri, pengajaran kitab Islam klasik, dan Kiyai/ustadz.

\section{Semiotika}

Semiotika berasal dari Yunani yang berarti tanda. Semiotika merupakan cabang ilmu yang berkaitan dengan tanda, baik dari sistem tanda dan proses yang berlaku bagi penggunaan tanda pda akhir abad ke-18. Seorang filsuf yang bersal dari Amerika yaitu Charles Chanders Peirce yang mempopulerkan semiotika. Semiotika merupakan saah satu ilmu tua yang baru. Semiotik adalah ilmu tanda-tanda yang meyakinkan bahwa fenomena komunikasi sosial dan kebudayaan. koponen tersebut dianggap sebagai sebuah tanda semiotik dalam menganalisis sistem-sistem, aturan-aturan, dan mengkonversikannya dengan tokoh pendirinya yaitu Ferdian de Saussure (1857-1913) dan Harles chanders peirce (1939-1914). Salah satu yang ditekankan Saussure adalah Bahasa harus dipelajari sebagai sebuah system tanda meskipun bukan menjadi satu-satunya tanda.

Tanda atau yang disebut dengan respresentamen oleh Charles $\mathrm{S}$ Peirce menyatakan bahwa sesuatu yang bagi seseorang mewakili sesuatu yang lain, dengan kata lain manusia dapat bernalar melalui tanda, (Indiawan, 2013:167). Peirce dalam teorinya menyatakan tiga elemen tanda yaitu sign (tanda), object 
(acuan tanda), dan interpretant (pengguna tanda) teori ini juga dikenal dengan teori segitiga makna, (Kriyantono, 2008: 266). Segitiga makna atau trikotomi ditinjau dari relasinya, maka tanda dibedakan dalam tiga bagian yaitu ikon, indeks dan symbol, (Zaimar, 2008: 5).

\section{a. Ikon}

Ikon merupakan hubungan berdasarkan kemiripan, karena menampilkan Kembali objek yang ditandainya sebagaimana bentuk fisik objek tersebut. Menurut Peirce ikon merupakan kesamaan yang paling sederhana antara tanda dan objeknya, (Noth, 2006: 121). Kefamiliaran suatu tanda maka semakin mudah dikenali sebagai suatu ikon. Pierce dari system triadiksemiotika membuat tiga subklasifikasi ikon, yaitu: 1) ikon tipologis, yaitu hubungan yang berdasarkan kemiripan bentuk, misalnya: lukisan realis atau peta. 2) ikon gramatik, yaitu hubungan berdasarkan kemiripan tahapan. Ikon gramatik juga diartikan sebagai gejala structural yang ditujukan dengan kemiripan rasional dan berurutan, misalnya diagram. 3) ikon Metafora, yaitu hubungan berdasarkan kemiripan meskipun tidak sepenuhnya/sebagian yang mirip, misalnya mawar dengan gadis, kumbang dengan laki-laki. b. Indeks

Indeks adalah hubungan yang mempunyai jangkauan eksistensial, eksistensial yang dimaksud adalah esisnya sesuatu tersebut disebabkan adanya sesuatu yang lain, atau hubungan sebab akibat (Zaimar, 2008: 5). Indeks diterjemahkan secara literal sebagai sesuatu yang dapat dilihat, didengar, dan mudah tercium baunya atau some sensory feature yang menghubungkannya dengan suatu objek tertentu. Indeks selalu dipahami berdasarkan frekuensi kemuncuannya. Artinya, untuk memahami tanda-tanda tersebut perlu paparan berulang terutama bagi manusia. Manusia belajar dari alam engenai tanda-tanda alam, sehingga semakin sering suau tanda muncu dan diikuti oleh suatu peristiwa atau kehadiran objek tertentu, semakin peka manusia terhadap indeks tersebut. Misalnya: 1)) awan gelap dipahami sebagai tanda (indeks) akan datangnya hujan, 2) dialek berbahasa menandakan seseorng berasal dari daerah tertentu.

c. Simbol
Menurut Peirce simbol adalah tanda yang hubungan antara tanda dan objek ditentukan oleh suatu peraturan yang berlaku umum (Zoest, 1993: 25). Symbol juga diartikan sebagai hubungan antara tanda dan denotatumnya yang ditentukan berdasarkan kesepakatan atau kebiasaan masyarakat misalnya: monas merupakan syimbol Jakarta.

\section{METODE PENELITIAN}

Metode penelitian yang digunakan dalam penelitian ini yaitu studi pustaka. Data dalam penelitian ini adalah kata/frasa khas pesantren dan makna syair yang mengandung gaya bahasa khas pesantren pada syair WRMPB. Data yang diperoleh disajikan dalam bentuk deskripsi yang dianalisis dengan menggunakan cara pandang semiotika menggunakan teori Charles Sanders Peirce Selanjutnya adalah melakukan analisis data menggunkan content analysis.

\section{HASIL DAN PEMBAHASAN Bentuk Gaya Bahasa Khas Pesantren Pada Syair WRMPB}

Stilistika selalu mengkaji dan memahami sastra dari segi kekhasan bahasa yang digunakan pengarang. Dalam penelelitian ini, peneliti memfokuskan pada bahasa pesantren yang menjadi bahasa khas pengarang. Syair WRMPB khususnya yang ditujukan pada anak keturunan dan abituren yaitu pada bagian syair kedua yang berjumlah 112 syair, pengarang banyak menggunakan kata/frasa pesantren sebagai diksi dalam syairnya. Setiap syair setidaknya memiliki satu kata khas pesantren. Khusus pada kata/frasa yang bersifat pesantren tersebut bahkan banyak ditulis menggunakan huruf kapital walaupun terletak di awal, tengah ataupun di akhir kalimat. Huruf kapital adalah huruf yang bersifat tegas, sehingga penggunaan huruf kapital pada suatu kata dapat memberikan kesan tegas dan serius di dalamnya (Charles Sanders Pierce dalam Budiman, 2003: 25), atau dengan kata lain pengarang ingin menegaskan atau memfokuskan pada kata-kata tersebut. Sesuai dengan paparan yang menuturkan bahwa sebuah tanda adalah sesuatu yang dapat mewakili sesuatu yang lain dalam berbagai kapasitas, hal tersebut dinamakan interpretan dari tanda sebelumnya yang mengacu pada objek. 
Teori Pierce tentang teori tanda dalam hal ini adalah kata/farasa pesantren pada syair WRMPB dapat di kaji dalam tiga unsur yaitu segitiga makna atau trikotomi yang meliputi object, sign, dan interpretant. Berdasarkan objek teori tanda pierce meliputi ikon, indeks, symbol. (1) Ikon adalah bentuk paling sederhana karena menampilkan kembali objek yang ditandainya sebagaimana bentuk fisik objek tersebut. (2) Indeks adalah sesuatu yang dapat dilihat, didengar atau mudah ditebak yang menghubungkannya dengan objek tertentu. (3) syimbol adalah bersifat alamiah atau diakui keberadaannya yang dikonvensikan dalam masyarakat.dan disepakati bersama walaupun bersifat arbiterer.

Table 1. Kata/frasa dalam syair WRMPB berdasarkan objeknya menurut teori Charles Sanders Pierce

\begin{tabular}{|c|c|}
\hline Jumlah & Kata/Frasa Pesantren \\
\hline $\begin{array}{c}5 \\
\text { Ikon }\end{array}$ & $\begin{array}{l}\text { Ma'mum (W.17), Imam (W.18), Ikhwan } \\
\text { (W.25), Ustadz (W.43), Takbir (W.89), Masya } \\
\text { Allah Wa Innalillah (W.10) Thariqat } \\
\text { (W.11,64,72,75,76), Bai'at (W.12), Su'ul } \\
\text { Khotimah (W.27), Nauzubillahi Min Zalika } \\
\text { (W.55), Alhamdulillah (W.71), Hasbunallah } \\
\text { (W.89), Hauqalah (W.89), Mukhlisin 108), } \\
\text { Shalihin (W.108), Innalillah (W.89), Ijazah } \\
\text { (W.11), Iblis (W.38,98), Sunnah Jama'ah } \\
\text { (W.40), Aqidah (W.40), Syari'ah (W.40,72), } \\
\text { Hizib (W.53,54), Lahad (W.66), Anbiya' } \\
\text { (W.64,67), Famasyaa'allah (W.89) }\end{array}$ \\
\hline 29 Index & $\begin{array}{l}\text { Hikmatul Quddus (W.2, 57), Mustawa (W.4), } \\
\text { Aqrabin (W.31), Bi'aunillahi Robbil Baroya } \\
\text { (W.5), Fidlalalim Mubin (W.31), Wirid (W.53), } \\
\text { Shalatunnahdlah (W.58), Kufayakun (W.57), } \\
\text { Shalawat Taisir (W.59), Rabanamfa'na (W.61), } \\
\text { Albasyirun Nazir (W.63), Al-Faqirul Haqir } \\
\text { (W.63), Atqiya' (W.67), Sufaha' (W.67,105), } \\
\text { Hasidin (W.69,71), Muhibbin (W.108), } \\
\text { Mufsidin (W.108), Rabbil 'Izzati (W.109). } \\
\text { Hasad (W.66,107), Fasad (W.66), }\end{array}$ \\
\hline $\begin{array}{c}16 \\
\text { Simbol }\end{array}$ & $\begin{array}{l}\text { Jannatul Ma'wa (W.4), Ibnu Saba' (W.35), } \\
\text { Khawarij (W.41), Al-Khidir (W.63), Hawwuz } \\
\text { (W.88). }\end{array}$ \\
\hline
\end{tabular}

Berdasarkan table di atas dapat disimpulkan bahwa kata/frasa khas pesantren banyak menggunakan kata kunci keislaman yang identik dengan bahasa Arab. Diksi yang pengarang gunakan cendrung menggunakan bentuk-bentuk sederhana. Hal tersebut dapat dilihat dari unsurunsur ikon yang mendominasinya, yaitu dari 50 kata/frasa khas pesantren terdapat 25 unsur ikon yaitu: Ma'mum, Imam, Ikhwan, Ustadz, Takbir, Masya Allah Wa Innalillah, Thariqat, Bai'at,
Su'ul Khotimah, Nauzubillahi Min Zalika, Alhamdulillah, Hasbunallah, Hauqalah, Mukhlisin, Shalihin, Innalillah, Ijazah, Iblis, Sunnah Jama'ah, Aqidah, Syari'ah, Hizib, Lahad, Anbiya', Famasyaa'allah. 20 unsur indeks yaitu: Hikmatul Quddus, Mustawa, Aqrabin, Bi'aunillahi Robbil Baroya, Fidlalalim Mubin, Wirid, Shalatunnahdlah, Kufayakun, Shalawat Taisir, Rabanamfa'na, Albasyirun Nazir, Al-Faqirul Haqir, Atqiya', Sufaha', Hasidin, Muhibbin, Mufsidin, Rabbil 'Izzati, Hasad, Fasad. 5 unsur simbol yaitu: Jannatul Ma'wa, Ibnu Saba, Khawarij, Al-Khidir, Hawwuz.

\section{Makna gaya bahasa khas pesantren dalam syair WRMPB}

Setiap kata atau frasa dalam syair memiliki makna dan pesan yang ingin disampaikan pembaca. Pemaknaan syair bergantung pada apa dan bagaimana memberi makna. Pada syair WRMPB dilakukan analisis dengan menyororti pada gaya bahasa khas pesantren yang digunakan dan pesan tersirat yang ingin disampaikan.

Berikut ini disajikan 10 syair yang mengandung gaya bahasa khas pesantren dan pemaknaannya:

W.2 Aduh sayang!

Setiap ujian banyak yang lulus

dan ada juga yang nyata LILUS

Memang begitu HIKMATUL

QUDDUS

untuk mencapai hasil yang bagus

Pada syair di atas terdapat satu frasa yang mengandung bahasa pesantren yaitu hikmatul quddus. Frasa tersebut terdiri atas dua kata yaitu hikmatul dan qudus. Hikmatul berarti kebijaksanaan atau pelajaran yang membawa hikmah dan quddus artinya suci. hikmatul quddus dalam bait syair tersebut dimaknai sebagai hikmah yang diberikan kepada pendiri yayasan atau pesantren yang dibangun oleh TGKH. Zainuddin Abdul Majid. Seorang pendiri yayasan dianggap memiliki kebijaksanaan yang tinggi dibandingkan dengan yang bukan menjadi bagian dari pendiri yayasan.

Selain itu, kandungan syair di atas menjadi salah satu alaram pengingat bagi abituren maupun alumni agar senantiasa menjaga hikmah suci sebagai main goal pendirian yayasan, bukan 
memanfaatkan hikmah sebagai medium memenuhi kepentingan diri sendiri.

W.4 Aduh sayang !

NW kembali menjadi KARYA cita-citanya setinggi MUSTAWA

Semoga tercapai JANNATUL MA'WA

Bi'aunillahi Robbil Baroya

Dalam bait syair di atas terdiri atas satu kata dan dua frasa pesantren. Kata mustawa berasal dari Bahasa Arab yang berarti tingkatan atau tempat yang agung. Kata ini juga identik diterjemahkan sebagai sebuah tempat yang terdapat pada lapisan langit Ke-9 sebagaimana Nabi Muhammad SAW. diperjalankan saat melaksanakan isra' mi'raj. Penggunaan kata Mustawa sebagai refresentasi dari keagungan dan cita-cita mulia yang hendak direalisasikan oleh organisasi NW. NW adalah karya maksudnya adalah bahwa NW menjadi wadah atau perkumpulan atau organisasi yang dapat menjadi penerjemah dan pelaksana cita-cita organisasi.

Bait yang mengandung frasa pesantren berikutnya adalah bait keempat yaitu "jannatul $m a$ 'wa" yang artinya syurga sebagai tempat berteduh. Pemilihan kata jannatul ma'wa sebagai pertanda dan tujuan akhir dari organisasi. Muara dari semua aktivitas organisasi adalah mengharapkan syurganya Allah SWT., tentunya dengan bi'aunillahi robbil baroya, yaitu atas pertolongan Allah SWT.

W.10 Aduh sayang!

Aku melihat banyaknya fitnah

karena anakda berpisah-pisah

tidak seturut pada ayahda

MASYA ALLAH WA INALILLAH

Frasa pesantren pada bait syair di atas terletak pada bait kedua dan kelima, yaitu Fitnah dan masya allah wa inalillah. Kata fitnah dalam Bahasa Arab berasal dari kata Fatana yang pada mulanya bermakna membakar emas untuk mengetahui kadar kualitasnya. Fitnah diartikan sebagai perbuatan menuduh orang lain dengan menyebarkan kebohongan. Namun pemaknaannya bergantung pada konteksnya yaitu bisa bermakna pada godaan yang menggiurkan atau yang lainnya. Fitnah dalam syair ini menunjukkan identitas kepekaan sosial dan spiritual TGKH. Zainuddin Abdul Majid dalam memahami kondisi keluarga dan jamaahnya.

Kata fitnah kemudian disusul oleh dua frasa yang bersinggungan secara makna- kontekstual. Kata masyaallah merupakan ungkapan dalam Islam terhadap suatu kejadian atau karena melihat dan mendengar sesuatu yang indah dan luar biasa. Sedangkan innalillah adalah ungkapan yang biasanya diucapkan saat saat orang meninggal dunia atau terkena musibah. Meskipun penggunaannya tidak dalam konteks tersebut semata melainkan terhadap segala hal yang datang seperti gempa bumi, banjir bandang, kebakaran, tsunami dan musibah-musibah lainnya.

W.11 Aduh sayang!

Dulu banyak yang kami Bai'at waktu IJAZAH dan nerima THARIQAT Sanggup membela selama hayat Sehidup semati sampai akhirat

Pada bait syair di atas, terdapat lima kata yang merupakan bahasa pesantren. yaitu yaitu bai'at, ijazah, thariqot, hayat dan akhirat. Kata bai'at artinya janji, Ijazah artinya izin atau lisensi, thariqot berarti tiang tempat berteduh, hayat artinya kehidupan dan akhirat berarti akhir. Bai'at dalam syair di atas adalah sebuah aksi dan ekspresi pengambilan sumpah atau janji terhadap seseorang untuk setia dan taat serta tunduk terhadap ketentuan bai'at. Dalam hal ini memberikan gambaran tentang banyaknya santri, jamaah yang berjanji terhadap loyalitas organisasi. Proses bai'at ini sebagai tanda memperoleh lisensi atau izin berjuang membesarkan organisasi. Thariqot dalam ini adalah jalan yang dilalui oleh pendiri organisasi, tidak menentang perintah pimpinan yang diamanahkan kepadanya.

Adapun hayat dimaknai sebagai pengorbanan dan perjuangan organisasi selama hidup. Selanjutnya Ijazah identik dengan pengakuan atas terselesaikannya pendidikan seseorang sebagai tanda lulus. Namun dalam Islam. Menurut para ahli hadist, Ijazah adalah salah satu cara menerima dan meriwayatkan suatu hadist. Maka menjadi beraneka ragam dalam makna dan penerapannya, sedangkan 
makna umumnya adalah menerima ilmu dari dari para guru.

W.31 Aduh sayang!

Kalau anakda berlain-lain

pastilah NW diteropong yang lain

Tidak lagi memandang AQRABIN

Hanya asing FIDLALALIM MUBIN

Bahasa pesantren dalam syair di atas terdapat pada bait ke empat dan kelima. Kata aqrabin artinya kerabat terdekat. Sedangkan fidlalalim mubin merupakan klausa dalam Bahasa Arab yang berarti kesesatan yang nyata. Bait pertama dimaksudkan untuk mengajak keturunannya untuk berimajinasi dan melihat masa depan, bahwasanya berpisah antar kerabat dalam satu wadah organisasi tidak hanya dipantau oleh anggota internal organisasi, melainkan juga diamati oleh jamaah diluar organisasi. Akibatnya organisasi dianggap remeh dan kesakralan organisasi oleh akrabiin tidak lagi menjadi menjadi pemantik spirit jamaah, bahkan rentan bercerai, tak mau akur dan asing.

W.40 Aduh sayang!

Asas NW jangan diubah

Sepanjang masa sepanjang sanah

SUNNAH JAMA'AH dalam 'Aqidah

MAZHAB SYAFI’I dalam Syari’ah

Kata pesantren dalam bait syair di atas adalah sanah, sunnah jama'ah, mazhab dan syariah. Kata sanah berasal dari Bahasa Arab yang berarti baik sekali atau pandai. Adapun sunnah jama'ah Artinya sunnah waljamaah. Atau orang-orang yang mengikuti sunnah rasulullah SAW dan berada dalam jamaah kaum muslimin. Sunnah secara bahasa berasal dari kata sanna yang artinya jalan atau jalan yang biasanya ditempuh atau kebiasaan aturan agama yang didasarkan atas segala apa yang dinukilkan kepada rasulullah SAW. Baik perbuatan, sikap dan kebiasaan yang tidak pernah ditinggalkannya. Jamaah artinya kumpulan atau rombongan orang beribadah.

Kata syariah artinya hukum. Makna syariah disini adalah hukum yang mengacu pada mazhab atau pendapat iman tentang hukum agama, dalam hal ini adalah Imam Syafii. Oleh karena itu, kata mazhab diartikan sebagai jalan yang dilalui dan dilewati dan menjadi tujuan seseorang baik konkret maupun abstrak.

W.55 Aduh sayang!

Ada pula selalu mencela

orang berhizib dihina dina

Akhirnya mati secara gila

NAUZUBILLAHI MIN ZALIKA.

Frasa pesantren pada bait syair di atas terdapat pada bait kelima yaitu nauzubillahi min zalika yang artinya aku berlindung dari yang demikian itu yaitu berlindung terhadap orang yang senang mencela dan menghina dina. Pesan ini diperuntukkan bagi orang yang mencela dan menghina hizib, doa-doa yang termuat dalam hizib.

W.57 Aduh sayang!

"KUNFAY AKUN" kontak nan halus menjadi penawar segala nufus Untuk mencapai HIKMATUL QUDDUS

perlu dibaca terus menerus

Frasa pesantren pada syair di atas adalah kunfayakun yang artinya jadilah maka jadilah. Artinya apapun yang dikehendaki allah akan terjadi. Frasa ini menggambarkan kemahakuasaan Allah SWT. Frasa ini juga merupakan kalimat perintah dan larangan. Adapun Nufus artinya kepedulian antar sesama agar memperoleh hikmah yang suci.

W.58 Aduh sayang!

Sholat terhebat

"SHALATUNNAHDLAH"

Penuh faidah penuh Hikmah

perlu dibaca oleh anakdah

Walau sehari marroh wahidah

Kata pesantren dalam syair di atas adalah sholat yang berasal dari Bahasa Arab yang berarti doa. Dalam terminologinya sholat diartikan sebagai serangkaian kegiatan ibadah khusus atau tertentu yang dimulai dengan takbiratul ihram dan diakhiri dengan salam.

Frasa pesantren kedua adalah shalatunnahdlah, yaitu sebuah sholawat yang sering digunakan oleh jamaah NW sebelum memulai kegiatan atau yang popular dengan istilah sholawat nahdatain. Adapun kata pesantren yang ketiga adalah faidah yang artinya 
mamfaat, guna hikmah adalah renungan dan kesungguhan memanfaatkan ilmu-ilmu dan peristiwa. Serta melihat keterkaitan yang ada. Keempat adalah adalah marroh wahidah artinya sekali sehari. Dalam hal ini adalah penekanan pada pembacaan sholatunnahdhah sekurangkurangnya dibaca sehari sekali.

\section{KESIMPULAN}

Berdasarkan hasil penelitian dan pembahasan di atas dapat disimpulkan bahwa kajian stilistika pesantren pada wasiat renungan masa TGKH. Zainuddin Abdul Majid membahas dua aspek yaitu gaya bahasa khas pesantren dan makna yang terdapat pada gaya bahasa pesantren tersebut. Gaya bahasa pesantren ditandai oleh kekhasan diksi yang dipilih. Dari 112 syair, setidaknya setiap syair memuat satu kata atau frasa pesantren. Hal ini dicirikan oleh diksi berbahasa Arab atau bernuansa Islami. Selain itu, penulisan hurufnya menggunakan huruf kapital yang memberikan pesan penegasan, dengan kata lain bahwa pengarang ingin menegaskan dan memfokuskan pada kata-kata tersebut.

Mengacu pada teori Pierce sebagai grand theory, bahwa untuk membedah syair dilakukan memetakan ikon, indeks, dan simbol. (1) Ikon adalah bentuk paling sederhana karena menampilkan kembali objek yang ditandainya sebagaimana bentuk fisik objek tersebut. (2) Indeks adalah sesuatu yang dapat dilihat, didengar atau mudah ditebak yang menghubungkannya dengan objek tertentu. (3) simbol adalah bersifat alamiah atau diakui keberadaannya yang dikonvensikan dalam masyarakat.dan disepakati bersama walaupun bersifat arbiterer. Hasil analisis tentang gaya bahasa pesantren pada syair WRMPB diperoleh Kata/frasa pesantren yang berjumlah 48 terdiri dari 8 unsur ikon yaitu Imam, Ma'mum, Ikwan, Ustadz, Takbir. 25 unsur indeks yang terdiri dari kata/frasa Hikmatul Quddus, Mustawa, Jannatul Ma'wa, Abituren, Masya Allah Wa Innalillah, Thariqat, Bai'at, Su'ul Khotimah, Aqrabin, Fidlalalim Mubin, Wirid, Nauzubillahi Min Zalika, Shalatunnahdlah, Shalawat Taisir, Rabanamfa'na, Albasyirun Nazir, Al-Faqirul Haqir, Atqiya', Sufaha', Hasidin, Alhamdulillah, Hasbunallah, Hauqalah, Mukhlisin, Shalihin, Muhibbin, Mufsidin, Innalillah. dan 15 unsur syimbol yaitu Bi'aunillahi Robbil Baroya, Ijazah, Ibnu Saba', Sunnah Jama'ah, Aqidah, Khawarij, Hizib, Kufayakun, Al-Khidir, Hasad, Fasad, Lahad, Anbiya', Famasyaa'allah, Rabbil 'Izzati.

\section{Ucapan Terima Kasih}

Kami ucapkan terima kasih kepada mitra bestari dan pascasarjana Universitas Mataram yang telah berkontribusi dalam proses publikasi ilmiah ini.

\section{DAFTAR PUSTAKA}

Abdullah, M. (2006). Dekonstruksi Sastra Pesantran. Semarang: Fasindo Press.

Alisyahbana. (1950). Puisi Lama. Jakarta: Pustaka Rakyat.

Akmal. (2015). Kebudayaan Melayu Riau (Pantun, Syair, Gurindam). Jurnal Risalah, 26(4): 159-165.

Ahmad, M. (2015). Gagasan Nilai-Nilai Pendidikan Karakter Tgkh. M. Zainudin Abdul Madjid dalam Wasiat Renungan Masa Pengalaman Baru. El-hikam, 8(2): 233-266.

Al Fajri, M. S. (2017). A StylisticAnalysis of Linguistic Patterns in Chichamanda Ngozi Adichie's Purple Hibiscus. 2017. Advances in Language and Literary Studies. ISSN: 2203-4714 Vol. 8 No. 3; June 2017. https://doi.org/10.7575/aiac.alls.v.8n.3p .55.

Buena, M. D., (2019). Semantic deviations in Jose Garcia Villa's "Poem 130": A stylistic analysis. Asian Journal of English Language Studies (AJELS). Volume 7, December 2019.

Depdikbud. (1995). Kamus Besar Bahasa Indonesia. Jakarta : Depdikbud.

Dhofier, Zamakhsyari. (2011). Tradisi Pesantren: Studi Pandangan Hidup Kyai Dan Visinya Mengenai Masa Depan Indonesia. Jakarta: LP3ES.

Hafedh B. (2021). On Language, Translation and Comparative Stylistics, Meta, XLV, 3 , 2000494. https://doi.org/10.7202/002143ar. 
Hendra, Gunawan. (2016). Representasi Kearifan Lokal Suku Sasak Dalam Wasiat Renungan Masa Pengalaman Baru Karya Tuan Guru Kyai Haji Muhammad Zainuddin Abdul Majid. Nosi, 4(2): 128-139.

Hernandez H. Punla. (2017). A (Forensic) Stylistic Analysis of Adverbials of Attitude And Emphasis In Supreme Court Decisions In Philippine English. Indonesian Journal of Applied Linguistics, Vol. 7 No. 2, September 2017, pp. 455-466. https://doi.org/10.17509/ijal.v7i2.8354

Hidayati. (2017). Konsep Pendidikan Akhlak Dalam Buku Wasiat Reningan Massa Tuan Guru Kiyai Haji Muhammad Zainudin Abdul Majid. Tesis: FITK Sunan Kalijaga.

Izzatillah. (2019). Estetika Islam "Tinjauan Terhadap Syair Wasiat Renungan Masa Karya Tuan Guru Kyai Haji Muhammad Zainuddin Abdul Majid". (http://repository.uinjkt.ac.id/dspace/ha ndle/123456789/48092. Diakses 12 April 2021).

Khan, B. Abdul. (2015). Stylistic Analysis of the Short Story 'The Last Word' by Dr. A. $\mathrm{R}$. Tabassum, Advances in Language and Literary Studies, ISSN: 2203-4714, Vol. 6 No. 3; June.

Leech, G., \& Short, M. (2007). Style in fiction: A linguistic introduction to English fictional prose (2nd ed.). London: Longman.

Minderop, Albertine. (2005). Metode Karakterisasi Telaah Fiksi. Jakarta: Yayasan Obor Indonesia.

Nasip, A., Mahyuni \& Nuriadi. (2019). "Nilai Pendidikan, Sosial, Kultural, Dan Spiritual dalam Wasiat Renungan Masa Karya Tgkh. Zainuddin Abdul Madjid: Tinjauan Hermeneutika". LINGUA, 16(2): 271-284.

Pradopo, R. Djoko. (2012). Pengkajian Puisi. Yogyakarta: Gajah Mada University Press.

Pradopo, R. Djoko. (2007). Pengkajian Puisi. Yogyakarta: Gajah Mada University Press.
Ratna, N. Kutha. (2016). Stilistika: Kajian Puitika Bahasa, Sastra, dan Budaya. Yogyakarta: Pustaka Belajar.

. (2014). Stilistika: Kajian Puitika Bahasa, Sastra, dan Budaya. Yogyakarta: Pustaka Pelajar.

Rubini. (2015). Pendekatan Pendidikan atau Dakwah Para Wali di Pulau Jawa. Jurnal Komunikasi dan Pendidikan Islam, 4(1) 201-220.

Siradj, S. Agil. (1999). Pesantren Masa Depan, Wacana Pemberdayaan dan Transformasi Pesantren. Bandung: Pustaka Hidayah.

Wijaya, Herman. (2013). Analisis Wacana Lirik Lagu Wasiat Renungan Masa Karya Tgkh. M. Zainuddin Abdul Majid Tinjauan Kontekstual Dan Situasi Serta Aspek Gramatikal Dan Leksikal. Jurnal Education, 8(1): 65-80. 